\title{
Extremely Fine Pearlite by Continuous Cooling Transformation
}

\author{
K. M. Wu ${ }^{a, b}$ H. K. D. H. Bhadeshia ${ }^{b}$ \\ ${ }^{a}$ International Research Institute for Steel Technology, Wuhan University of \\ Science and Technology, Wuhan 430081, China \\ ${ }^{\mathrm{b}}$ Materials Science and Metallurgy, University of Cambridge, CB2 3QZ, U.K.
}

\begin{abstract}
An extremely fine, fully pearlitic structure with an interlamellar spacing 30-50 $\mathrm{nm}$ has been obtained during continuous cooling transformation at a rate as low as $0.1^{\circ} \mathrm{C} \mathrm{s}^{-1}$, of the steel that is normally used to produce nanostructured bainite. The solutes cobalt and aluminium have been added to accelerate the rate of reaction and reduce the interlamellar spacing by increasing the free energy of transformation. The range of cooling rates over which the fully pearlitic state can be achieved is characterised.
\end{abstract}

Key words: nanostructured pearlite, continuous cooling transformation, strong steel, alloy design

A new range of steels have been developed in which extremely fine plates of bainite can be obtained by isothermal transformation at low homologous temperatures in very large samples [1]; the material is now commercialised and the subject has recently been reviewed [2]. The alloys typically have a hypereutectoid composition Fe-1C-1.5Si-1.9Mn-1.3Cr-0.25Mo wt\%. During the course of experiments on the transformation of austenite under the influence of a 30 Tesla magnetic field, it was discovered that the continuous cooling transformation of austenite at $1^{\circ} \mathrm{Cs}^{-1}$ resulted in the development of pearlite with an interlamellar spacing of just 50-100 nm, whereas the pearlite was not present in the absence of the field $[3,4]$. Such fine pearlite, obtained using a simple heat treatment, has technological potential, but the use of strong magnetic fields is prohibitively expensive and possibly impractical. Such fine spacings have previously been achieved in very high-carbon steels containing $1.5-1.8 \mathrm{C}$ wt\%, but the microstructures obtained contained significant quantities of proeutectoid cementite. Similar spacings have been reported for plastically deformed pearlite [5] but the purpose here is to achieve interlamellar refinement by phase transformation. 
The reason why the magnetic field stimulated the formation of pearlite is the increase in the driving force for transformation from paramagnetic austenite into ferromagnetic ferrite and cementite. The purpose of the work presented here was to see whether the fine pearlite can be obtained by enhancing the driving force using alloying elements rather than an externally applied magnetic field.

Cobalt has long been known to increase the driving force for pearlite [6] and cobalt and aluminium increase the driving force for the formation of ferrite [7]. This characteristic of the two solutes has also been verified in the types of steels considered here [8]. It is these latter alloys, designed originally for accelerated bainitic transformation, which inspired the alloy design in the present work where we wished to investigate the formation of pearlite during continuous cooling. Larger concentrations of aluminium and cobalt are used compared with the earlier research [8]; the compositions are listed in Table 1. Alloy 1 contains Co and $\mathrm{Al}$ and Alloy 2 does not. Samples were cut and then homogenised at $1200^{\circ} \mathrm{C}$ for $48 \mathrm{~h}$ in a vacuum furnace. Then they were left in the furnace to cool down to room temperature over a period of $24 \mathrm{~h}$ to obtain a coarse and soft fullly-pearlitic microstructure which can be readily machined, into cylindrical sample $8 \mathrm{~mm}$ and $12 \mathrm{~mm}$ long.

Table 1

Chemical compositions of the alloys studied, wt $\%$

\begin{tabular}{cccccccccccc}
\hline Alloy & $\mathrm{C}$ & $\mathrm{Si}$ & $\mathrm{Mn}$ & $\mathrm{Mo}$ & $\mathrm{Cr}$ & $\mathrm{Co}$ & $\mathrm{Al}$ & $\mathrm{P}$ & $\mathrm{S}$ & $\mathrm{V}$ & $\mathrm{Ni}$ \\
\hline 1 & 0.78 & 1.60 & 2.02 & 0.24 & 1.01 & 3.87 & 1.37 & 0.002 & 0.002 & - & - \\
2 & 0.79 & 1.59 & 1.94 & 0.30 & 1.33 & - & 0.013 & $<0.002$ & - & 0.11 & 0.02 \\
\hline
\end{tabular}

Continuous cooling transformation experiments were performed on a Thermecmaster thermomechanical simulator. Samples were heated at a rate of $10^{\circ} \mathrm{C} \mathrm{s}^{-1}$ and held at $1000^{\circ} \mathrm{C}$ for 10 minutes for austenisation prior to transformation. The samples were then continuously cooled to room temperature at a cooling rate ranging from 0.02 to $2^{\circ} \mathrm{Cs}^{-1}$. After heat treatment specimens were polished and etched with $3 \%$ nital solution for optical, scanning and transmission electron microscopy. Specimens for transmission microscopy were machined from $3 \mathrm{~mm}$ diameter rods which were sliced into $100 \mu \mathrm{m}$ discs, and ground down to $50 \mu \mathrm{m}$ thickness using 1200 grit silicon carbide paper. The discs were then electropolished using a mixture of $5 \%$ perchloric acid, $15 \%$ glycerol and $80 \%$ methanol. The resulting foils were examined using a JEOL JEM-200CX transmission electron microscope operated at $200 \mathrm{kV}$.

Vickers hardness tests are reported as the average of at least ten indentations made using a $1 \mathrm{~kg}$ load. Measurements of the interlamellar spacing of pearlite were performed using SEM and TEM images, with ten fields studied for each case; the statistical uncertainties quoted refer to $\pm 1 \sigma$. The true interlamellar 
spacing $L$ was derived from the mean value $\bar{S}_{R}$ of measurements on random sections according to $S=0.5 \bar{S}_{R}[9,10]$.

Typical measurements for Alloy 1 are illustrated in Fig. 1 with pearlite forming over the temperature range $695-661^{\circ} \mathrm{C}$ at a cooling rate of $0.05^{\circ} \mathrm{C} \mathrm{s}^{-1}$, with mostly martensite forming when the cooling rate is increased by a factor of 10. Further data are summarised in Table 2. Alloy 1 is able to transform into pearlite for cooling rates less than $0.1^{\circ} \mathrm{Cs}^{-1}$ whereas the corresponding rate for Alloy 2 has to be less than $0.05^{\circ} \mathrm{Cs}^{-1}$ and transformation is suppressed to lower temperatures when compared against the steel containing the cobalt and aluminium. As expected, both alloys were found to show increasing quantities of martensite at greater cooling rates. It should be noted that bainite in these steels requires too long to form during continuous cooling at the rates studied, which is why the residual phase after pearlitic transformation etches white relative to pearlite itself; optical micrographs for the two alloys cooled at $0.1^{\circ} \mathrm{Cs}^{-1}$ from the austenitisation temperature are given in Fig. 2.

Table 2

Data obtained from dilatometric experiments. The symbols $P$ and $\alpha^{\prime}$ stand for pearlite and martensite respectively.

\begin{tabular}{cccccc}
\hline Alloy & $\dot{T} /{ }^{\circ} \mathrm{C} \mathrm{s}^{-1}$ & Start $T /{ }^{\circ} \mathrm{C}$ & Finish $T /{ }^{\circ} \mathrm{C}$ & Time interval / s & Microstructure \\
\hline Alloy 1 & 0.02 & 695 & 682 & 514 & $P$ \\
& 0.05 & 694 & 680 & 438 & $P$ \\
& 0.1 & 683 & 661 & 198 & $P$ \\
& 0.5 & 197 & & & $P+\alpha^{\prime}$ \\
& 1 & 199 & & & $\alpha^{\prime}$ \\
& 2 & 197 & & 1100 & $\alpha^{\prime}$ \\
\hline \multirow{2}{*}{ Alloy 2} & 0.02 & 689 & 669 & 546 & $P$ \\
& 0.05 & 677 & 650 & 235 & $P+\alpha^{\prime}$ \\
& 0.1 & 662 & 639 & & $\alpha^{\prime}$ \\
& 0.5 & 131 & & & $\alpha^{\prime}$ \\
& 1 & 132 & & & $\alpha^{\prime}$ \\
\hline
\end{tabular}

Figure 3 shows typical scanning and transmission electron micrographs which reveal the extremely fine pearlite obtained, particularly in Alloy 1, when cooled at the slow rate of $0.02^{\circ} \mathrm{Cs}^{-1}$ in order to generate fully pearlitic microstructures. Quantitative measurements giving the true interlamellar spacing as a function of cooling rate are presented in Fig. 4a where it is seen that $S \approx 44-96 \mathrm{~nm}$ for Alloy 1 and $S \approx 80-128 \mathrm{~nm}$ for Alloy 2 . A greater cooling rate leads to a finer spacing by suppressing the transformation to lower temperatures, but there is an upper limit to the cooling rate determined by incomplete transformation, as shown in Table 2. 
Corresponding hardness data for just the fully pearlitic samples are shown in Fig. 4b where they are plotted as a function of $S^{-1}$ [11]. It is interesting that all the data fall roughly on the same line, indicating that the major differences in the hardness of fully pearlitic samples is due to variations in interlamellar spacings. Note that the strength of pearlite is sometimes analysed in terms of a Hall-Petch relationship $S^{-1 / 2}$ but this is difficult to justify on the basis of the mechanism when considering undeformed, fine pearlite.

It has been demonstrated that the addition of cobalt and aluminium to a steel normally used to produce low-temperature bainite, permits the alloy to transform completely into pearlite at slow cooling rates. This is because of the well-known effect of these solutes in enhancing the driving force for the transformation of austenite into pearlite. The interlamellar spacing that can be obtained in this way can be as small as $50 \mathrm{~nm}$ (hardness $422 \mathrm{HV}$ ), which is somewhat finer than that transformed under the influence of a $30 \mathrm{~T}$ magnetic field.

Furthermore, the Co and $\mathrm{Al}$ containing steel is demonstrated to achieve finer interlamellar spacings even though it transforms at a higher temperature than the alloy free from these solutes. A comparison of the two alloys shows that the major differences in their hardnesses in the fully pearlitic state can be explained purely in terms of the variations in interlamellar spacing.

Further work is planned to understand the partitioning of solutes during the course of the austenite to pearlite transformation. This could be revealed by partial transformation into pearlite, followed by isothermal transformation at a lower temperature in order to preserve some austenite and the solute distribution at the austenite-pearlite interface.

Professor Wu gratefully acknowledges the financial support from China Scholarship Council (CSC) and the State Ministry of Education (NCET-05-0680), and the invaluable assistance from colleagues in at the University of Cambridge. 


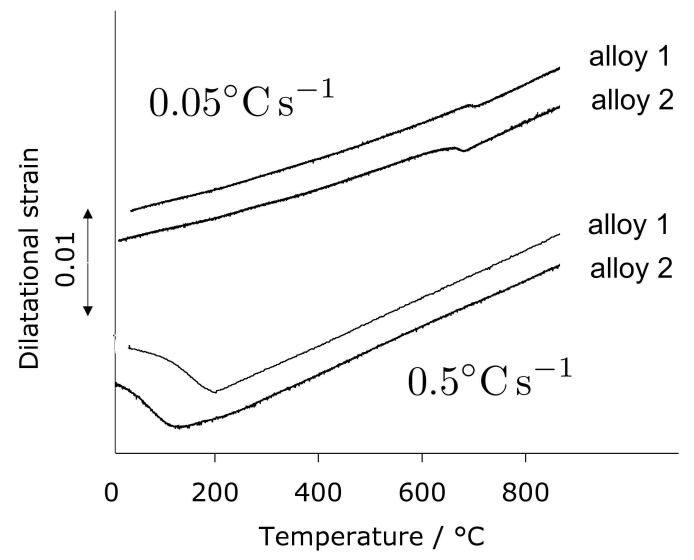

Fig. 1. Dilatational strain as a function of temperature.
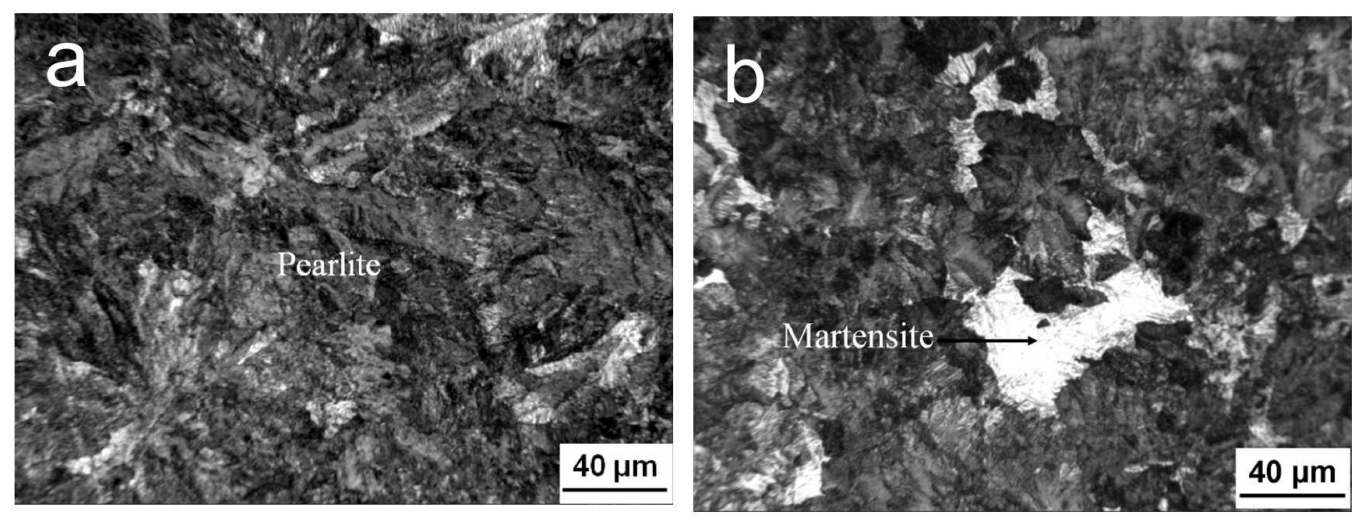

Fig. 2. Optical micrographs of samples cooled at $0.1^{\circ} \mathrm{Cs}^{-1}$. (a) Alloy 1. (b) Alloy 2. 

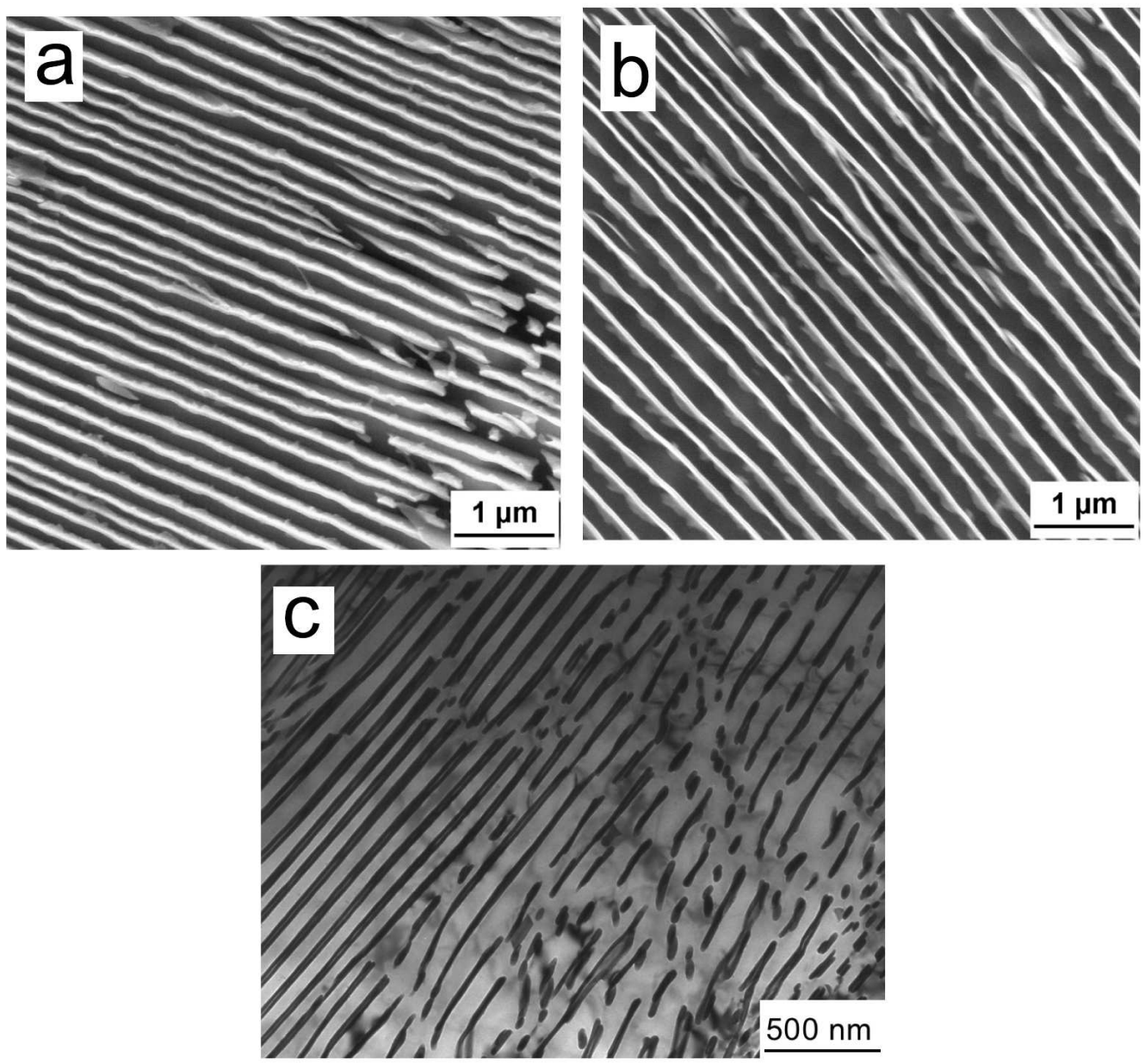

Fig. 3. Samples cooled at $0.02^{\circ} \mathrm{Cs}^{-1}$. (a) SEM image of Alloy 1; (b) SEM image of Alloy 2; (c) TEM image of Alloy 1.
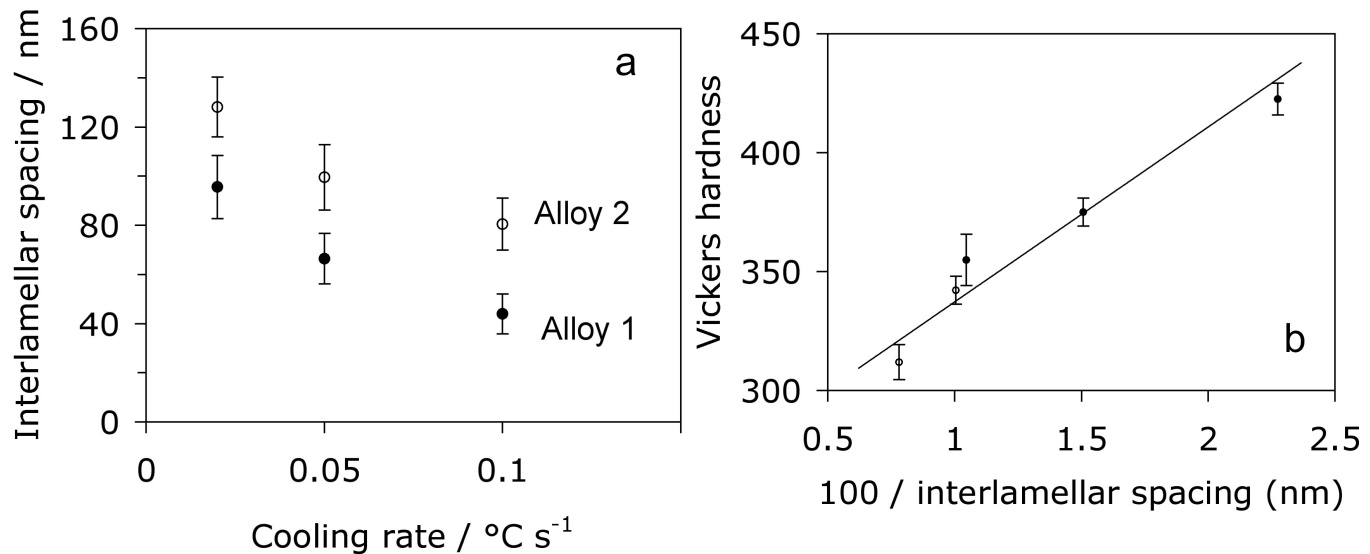

Fig. 4. (a) Relationship between interlamellar spacing and cooling rate. (b) Hardness of fully pearlitic samples as a function of the inverse of the interlamellar spacing. 


\section{References}

[1] F. G. Caballero, H. K. D. H. Bhadeshia, K. J. A. Mawella, D. G. Jones, P. Brown: Mat. Sci. and Techn. 18 (2002) 279.

[2] H. K. D. H. Bhadeshia: Proc. Royal Society of London A 466 (2010) 3.

[3] R. A. Jaramillo, S. S. Babu, G. M. Ludtka, R. A. Kisner, J. B. Wilgen, G. Mackiewicz-Ludtka, D. M. Nicholson, S. M. Kelly, M. Murugananth, H. K. D. H. Bhadeshia: Scr. Mat. 52 (2004) 461.

[4] R. A. Jaramillo, S. S. Babu, M. K. Miller, G. M. Ludtka, G. MackiewiczLudtka, R. A. Kisner, J. B. Wilgen, H. K. D. H. Bhadeshia: J. M. Howe, D. E. Laughlin, J. K. Lee, U. Dahmen, W. A. Soffa (Eds.), Solid-Solid Phase Transformations, TME-AIME, Warrendale, USA (2005) 873.

[5] V. T. L. Buono, B. M. Gonzalez, T. M. Lima, M. S. Andrade: J. Mat. Sci. 32 (1997) 1005.

[6] R. F. Mehl, W. C. Hagel: Prog. Met. Phys 6 (1956) 74.

[7] H. I. Aaronson, H. A. Domian, G. M. Pound: TMS-AIME 236 (1966) 781.

[8] C. Garcia-Mateo, F. G. Caballero, H. K. D. H. Bhadeshia: ISIJ International 43 (2003) 1821.

[9] F. G. Caballero, C. G. de Andrés, C. Capdevila: Mat. Charact. 45 (2000) 111.

[10] F. G. Caballero, C. G. de Andrés, C. Capdevila: Scr. Mat. 42 (2000) 537.

[11] K. K. Ray, D. Mondal: Acta Metall. Mater. 39 (1991) 2201. 